\title{
Entre ficcionalidade e objetivismo: 0 caso clínico como locus de elaboração conceitual do material fatual ${ }^{1}$
}

\author{
Between fiction and objectivism: the clinical case as locus of \\ conceptual elaboration of the factual material
}

\section{Helio Honda}

Docente do Departamento de Psicologia da Universidade Estadual de Maringá, Maringá, PR - Brasil, e-mail: hhonda@uem.pr

\section{Resumo}

O artigo trata da relação entre clínica e metapsicologia a partir da discussão do papel do caso clínico na elaboração conceitual freudiana. Parte da exposição de duas perspectivas distintas na consideração do papel do caso clínico, uma que o toma como ficção e outra que valoriza a recolha de dados brutos. Mostra, na sequência, que em Freud não se trata nem de ficção nem de empiria pura, mas que o caso clínico teria como função introduzir um domínio epistêmico novo. Por fim, analisa algumas ideias de Freud, segundo as quais pressuposições e hipóteses teóricas encontrar-se-iam indissoluvelmente entrelaçadas com os dados clínicos, de modo que o caso clínico pode ser considerado como lugar de elaboração conceitual do material fatual na construção da metapsicologia.

Palavras-chave: Caso clínico. Conceitos em psicanálise. Metapsicologia.

1 Trabalho vinculado ao Projeto de Pesquisa financiado pelo CNPq. 


\section{Abstract}

The article deals with the relationship between clinical work and Metapsychology from the discussion of the role of case history in the Freudian conceptual elaboration. It starts with the exhibition of two different perspectives on the role of the case history, one that takes it as fiction and one that values the collection of raw data. It shows later that in Freud it is neither fiction nor pure empiricism, but that the case history would have the function of introducing a new epistemic domain. Finally, it analyzes some ideas of Freud, according to which theoretical assumptions and hypotheses would be inextricably intertwined with the clinical data, so that the case history can be considered as a locus of conceptual elaboration of the factual material in the construction of Metapsychology.

Keywords: Case history. Concepts in psychoanalysis. Metapsychology.

\section{Introdução}

Meu objetivo é problematizar a questão da relação entre metapsicologia e clínica, tomando como objeto de análise o caso clínico em Freud. Para tanto, vou expor inicialmente algumas questões envolvidas na discussão da natureza dos históricos de caso para distinguir duas posições extremas em relação ao caso clínico: uma que tende a considerar o caso como uma ficção, e outra que procura resgatar a objetividade do caso pela defesa da apresentação de dados clínicos brutos. A partir dessas duas posições, vou tentar mostrar que nenhuma delas é consistente com o caso clínico em Freud, porque nele pressuposições e hipóteses teóricas encontram-se entrelaçadas com os dados clínicos. A ideia é apresentar indicações de que a metapsicologia emerge do caso clínico considerado como lugar de elaboração conceitual do material fatual.

\section{Narrativa literária ou empiria pura}

Uma opinião corrente sobre o caso clínico procura evidenciar o seu aspecto ficcional, quer dizer, por se tratar de uma narrativa, o 
efeito de convencimento resultante da leitura de um relato estaria relacionado muito mais às suas qualidades linguísticas e estéticas do que a qualquer caráter demonstrativo. Essa opinião pode ter sido afiançada pelo próprio Freud, porque, em uma das passagens mais citadas dos "Estudos sobre Histeria", de 1895, podem-se encontrar algumas indicações nesse sentido. Na história do caso Elisabeth Von R., Freud (2007a, p. 174) escreve:

Nem sempre fui psicoterapeuta, mas fui educado, como outros neuropatologistas, em diagnósticos locais e prognósticos em eletroterapia, e, por isso, resulta singular também para mim que as histórias clínicas que escrevi sejam lidas como romances curtos, e nelas estejam ausentes, por assim dizer, o caráter de seriedade próprio do científico. [...] Ocorre que o diagnóstico local e as reações elétricas não se aplicam ao estudo da histeria, enquanto que uma exposição em profundidade dos processos anímicos como a que estamos habituados a receber do poeta permite-me obter, mediante a aplicação de algumas poucas fórmulas psicológicas, um tipo de conhecimento [Einsicht] sobre o desenrolar de uma histeria.

Além de conter metáforas poéticas e poder ser lido como "contos literários", outro fator que pode reforçar a opinião acerca do caráter ficcional dos relatos de caso tem a ver com o fato de serem construções elaboradas no interior da relação transferencial. Isso implica que a escolha do caso a ser relatado e os dados selecionados na sua redação seriam contingenciais e poderiam ser até mesmo tendenciosos; enfim, que na construção de um caso clínico estariam presentes motivações nada objetivas. Por essa via de argumentação, alguns autores sustentam que o caso clínico deve ser entendido como uma ficção (SOUZA, 2000), sem valor demonstrativo, portanto; sua elaboração visaria a persuadir o leitor acerca de uma hipótese clínica ou, no máximo, teria um valor didático.

Além da opinião sobre o caráter ficcional do caso clínico, sobretudo, os casos escritos por Freud são alvo de duras críticas. As mais radicais tendem a considerá-los como falhos, quando não enganosos. Em artigo publicado em 1997 (reeditado em francês em 1999), Mahony 
(1999, p. 121) pergunta: "que valor atribuir hoje aos casos clínicos de Freud?". Nesse artigo, Mahony distingue, entre as críticas endereçadas aos casos clínicos de Freud, aquelas que teriam como finalidade mostrar como as instituições psicanalíticas tendem a preservar um Freud idealizado, idealização que se estenderia à opinião que fazemos dos próprios históricos de caso de Freud, seus grandes casos consagrados (como Dora, Hans, Schreber, homem dos ratos e homem dos lobos). Essas críticas visariam a mostrar duas coisas: 1) que não se pode dar crédito aos casos clínicos legados por Freud; e 2) que é necessário denunciar a interpretação tendenciosa que a instituição psicanalítica faz desses casos (MAHONY, 1999).

Entre essas críticas, uma lembra-nos de certas modificações introduzidas por Freud no relato do caso do homem dos ratos. Uma comparação detalhada entre as notas do caso deixadas por Freud e o relato do caso conforme publicado revelaria algumas divergências. Segundo Mahony, em seu livro de 1986 dedicado ao caso do homem dos ratos, os fatos teriam sido seriamente manipulados por Freud em pontos essenciais. Para reproduzir a voz dos críticos, escreve Mahony (1999, p. 126): "em outros termos Freud deformou a verdade; ele mentiu. A utilidade clínica do caso diminui, portanto, na mesma medida dessas importantes distorções históricas".

E mais: além das manipulações introduzidas no caso do homem dos ratos, os partidários dessa crítica consideram que alguns episódios relativos ao manejo clínico de Freud também deveriam ser questionados a fim de tentar desfazer a imagem idealizada de Freud e obter uma visão crítica da clínica por ele praticada. Um exemplo mencionado por Mahony é o episódio Elma Vacos, paciente de Ferenczi, que, após tomá-la como sua amante, encaminha-a para continuar tratamento com Freud. Após alguns meses de tratamento, Freud teria revelado a Ferenczi informações sobre a intimidade da paciente, que, por sua vez, demanda a este sobre o conteúdo das informações reveladas por aquele. Diante do impasse criado, Freud teria interrompido bruscamente o tratamento, reenviando a paciente a Ferenczi (HAYNAL, 1995). Outro episódio mencionado é o de Horace Frink, fundador da Associação Psicanalítica Americana, igualmente 
paciente de Freud, para quem este teria dado conselhos nada analíticos, como o de separar-se de sua esposa para desposar uma rica herdeira de banco, cujas consequências para o tratamento teriam sido as mais desastrosas (MAHONY, 1999).

Sabemos que não faltam críticas a Freud e ao seu manejo técnico. Também não faltam opositores fervorosos à psicanálise. Para o que nos interessa neste artigo, penso não ser necessário mencionar exemplos adicionais de "escorregadas" técnicas de Freud, porque exemplos desse tipo também não faltam, sobretudo, em sua correspondência com Fliess (FREUD, 1986).

Em vista desse tipo de crítica endereçada aos casos clínicos de Freud e a seu manejo clínico, parece claro que não foi sem motivo que se registrou na história recente da psicanálise a sugestão de que "os estudos de casos mais conhecidos de Freud fossem retirados dos programas dos Institutos de Formação Psicanalítica, em razão de diferenças técnicas entre a prática de Freud e a dos psicanalistas modernos" (WIDLÖCHER, 1996, p. 231). Com base não apenas na opinião de que os progressos técnicos alcançados pela psicanálise de hoje justificariam retirar o estudo dos casos de Freud do corpus psicanalítico, revela-se também entre essa corrente de pós-freudianos a preocupação com a objetividade do relato dos fatos clínicos; daí a proposta de substituir os relatos mais extensos de uma história clínica "por relatos textuais de todas as sessões ao longo do tratamento. A ideia seria a mesma: fornecer aos pesquisadores material 'bruto' sobre o qual pudessem conduzir suas investigações"' (WIDLÖCHER, 1996, p. 231).

Proposta do gênero teria sido enunciada por Jacob Arlow, no Instituto de Psicanálise de São Francisco, em 1991. Arlow (apud MAHONY, 1999, p. 123) teria argumentado que "mesmo se se reconhece ainda alguma validade ao modelo tradicional, não se pode negar que os progressos da psicanálise exigem sua atualização e também um freio aos estudos sobre os sonhos de Freud e as histórias de caso". Outros argumentos de Arlow (apud MAHONY, 1999, p. 123): "a psicanálise é a única profissão que faz referência a manuais mais que centenários". Ou ainda: "se é verdade que 'a psicanálise estava no centro da vida de Freud, a vida de Freud não é central para a psicanálise como ciência'” (ARLOW apud 
MAHONY, 1999, p. 123). Uma espécie de conclusão a que teria chegado Arlow é reproduzida por Mahony com essas palavras:

as histórias de caso de Freud não nos ensinam senão poucas coisas sobre a técnica clínica de que necessitamos. A psicanálise como disciplina científica do século XX parece uma práxis eminentemente oral, no campo da clínica como no campo da supervisão. [...] Deixemos as exegeses acrobáticas da vida e dos históricos de caso de Freud aos eruditos letrados, cujos exercícios especulativos feitos na tranquilidade do escritório [en chambre] estão muito longe das provas e dos métodos empíricos de nossa ciência clínica (ARLOW apud MAHONY, 1999, p. 123-124).

Convém resumir o que foi dito até aqui separando essas críticas e apresentando-as como duas posições extremas na consideração do caso clínico: uma para a qual o caso clínico seria uma narrativa ficcional elaborada no interior da transferência e, por isso mesmo, permeada de conteúdos subjetivos em diferentes graus, portanto, passíveis não apenas de erros, mas também de manipulações deliberadas. Nesse sentido, vale recordar a crítica endereçada por Fliess a Freud, presente na carta de 7 de agosto de 1901. Fliess teria acusado Freud de ser um "leitor de pensamentos [que] lê apenas seus próprios pensamentos nas outras pessoas" (FREUD, 1986, p. 448). Portanto, não deveríamos atribuir valor objetivo a um relato de caso clínico, já que não serviria como uma prova nem teria qualquer outra função demonstrativa. O caso teria, no máximo, um valor de ilustração; seria um artifício retórico, redigido com a finalidade de produzir prazer estético e persuadir o leitor acerca da tese em pauta.

Outra posição seria aquela que, ao abrir mão do estudo dos casos clínicos elaborados por Freud (e de outros psicanalistas), visaria a resgatar a objetividade dos dados clínicos brutos mediante a apresentação de relatos integrais de sessões de análise (muitas vezes gravadas). Em outras palavras, a crença subjacente a esse tipo de proposta é a de que seria possível fornecer material "bruto" para os estudos psicanalíticos objetivos. Trata-se, como se pode ver, da retomada de uma crença antiga - demonstrada como equivocada pelos filósofos da ciência - na possibilidade de se obter dados empíricos brutos sobre os quais diferentes 
pesquisadores poderiam exercer de forma objetiva e imparcial a atividade analítica que garantiria a neutralidade da ciência.

\section{Nem narrativa ficcional, nem empiria pura: do caso clínico é derivado etwas Neues}

Para tentar escapar desse esquema maniqueísta, vou partir de uma citação de Freud extraída das páginas iniciais do caso do homem dos lobos, publicado em 1918, porque considero que nesse lugar Freud assinala justamente a impropriedade de ambas as posições antes descritas. Escreve ele:

não posso escrever a história de meu paciente em termos puramente históricos ou pragmáticos; não posso oferecer nem uma história do manejo [Behandlung] no tratamento nem uma [história] da doença, senão que serei obrigado a combinar entre si ambos os modos de exposição. Sabe-se que não se encontrou nenhum caminho para acomodar de algum jeito, no relato [Widergabe], a convicção resultante da análise. E para isso não teria serventia registros protocolares completos dos acontecimentos nas sessões de análise; sua consecução também está excluída pela técnica do manejo no tratamento. Portanto, não se publica tais análises para produzir convicção em quem até o momento teve uma conduta de rejeição e incredulidade. Esperase unicamente apresentar algo novo [etwas Neues] para aqueles pesquisadores que adquiriram convicção por suas próprias experiências com os enfermos (FREUD, 2007c, p. 14).

Quer dizer, por um lado, não se deve esperar do relato de um caso clínico que ele seja convincente, por mais que a história clínica apresente mais força persuasiva e valor estético do que outras narrativas científicas, já que, como disse Freud, não se publica um relato de caso com a intenção de convencer o leitor incrédulo. Por outro lado, o registro detalhado do desenrolar de uma sessão analítica também estaria colocado fora de questão pelos próprios princípios da técnica; quer dizer, pouco adiantaria a recolha de dados "brutos" em quantidade, já que o problema maior é dar expressão linguística à convicção alcançada pelo analista em relação ao processo de cura. Em outras palavras, 
a dificuldade é pôr no papel a experiência interna, de compreensão metapsicológica, obtida pelo analista ao longo do tratamento.

Mas, além do aspecto negativo, pelo qual Freud exclui do caso clínico o que não se deve esperar dele, pode-se ler em suas palavras uma indicação mais positiva, porque, diz ele, com a publicação de um caso clínico, "espera-se unicamente apresentar algo novo para pesquisadores que adquiriram convencimento por suas próprias experiências com os enfermos" (FREUD, 2007c, p. 14). Há aqui dificuldades sérias. Afinal, estaria o relato clínico endereçado unicamente para psicanalistas e àqueles com experiência clínica? O algo novo [etwas Neues] veiculado pelo relato visaria, então, a oferecer uma possibilidade nova de ordenação da experiência clínica? Ultrapassa o escopo deste artigo analisar esses problemas. Aqui, gostaria apenas de enfatizar essa função do caso clínico: apresentar "algo novo" para os pesquisadores. Como entender esse "algo novo" [etwas Neue] anunciado pelo relato de um caso clínico? Em Freud teríamos ainda que considerar que esse "algo novo", essa novidade, é anunciada mediante casos singulares. Afinal, a tendência de Freud parece ser a de efetuar generalizações a partir de casos únicos, como o faz, por exemplo, com os resultados do caso Anna O. para as histerias; o sonho de injeção de Irma para os sonhos em geral (HONDA, 2008). Resta saber qual seria o sentido dessa generalização possibilitada pelo caso clínico único.

Segundo Widlöcher (1999, p. 199), “Se o método indutivo quantitativo tem sobretudo por interesse verificar a regularidade de um evento observado, o método do caso único tem sobretudo por objetivo descobrir novos objetos de conhecimento". Isso ocorre porque

se pôde mostrar que esse método [do estudos de caso], antes de conduzir a toda generalização, definiria um domínio no qual o enunciado que se extrai da experiência única é verdadeiro para ao menos um indivíduo. Ele [o método] descreve um domínio (aquele da raiva curada pela vacinação, as alucinações provocadas pelo LSD 25 ou afasias por lesões corticais) e não uma população de indivíduos (WIDLÖCHER,1999, p. 198). 
Nesse sentido é que se diria que a metodologia dos estudos de casos individuais não se orienta pela norma estatística, mas pela noção de tipo, resultando daí a construção de modelos explicativos.

Assim, se é correto dizer que as inferências extraídas de um caso clínico único visam a introduzir um domínio epistêmico novo, é porque essa inferência vale ao menos para um caso. Na esteira de Marshal Edelson (1984, 1988), poder-se-ia dizer que "uma única observação psicanalítica permite mostrar que existe um domínio, o da psicanálise, e que um caso ao menos pertence a ele. Isso se aplica, aliás, a todas as pesquisas que utilizam o caso singular" (WIDLÖCHER, 1990, p. 298). E qual seria esse domínio novo inferido por Freud a partir de seus estudos de caso, senão o domínio da realidade dos processos inconscientes?

Assim, ao compreendermos essa peculiaridade da metodologia dos estudos de caso, compreendemos também por que na introdução do capitulo 7 da Interpretação dos sonhos, de 1900, Freud ressalva que a nova teoria do aparelho psíquico aí apresentada não deve ser tomada como fundamentada enquanto não forem corroboradas mediante estudos de outros fenômenos psíquicos, porque consistem em hipóteses sobre um domínio epistêmico novo, derivado do estudo isolado dos sonhos, e de modo geral de um sonho singular, o sonho-modelo de injeção de Irma. Vale a pena ler o texto de Freud:

um conhecimento [Aufschluss] acerca da construção e do modo de trabalho do instrumento da alma [Seeleninstruments] não pode ser obtido, ou ao menos não pode ser fundamentado, por meio da investigação cuidadosa do sonho ou de outra operação [anímica] isoladamente. Mas, para esta finalidade será preciso juntar o que o estudo comparativo de uma série completa de operações psíquicas evidenciar como constante necessária [als konstant erforderlich]. Então, as hipóteses psicológicas que nós extraímos da análise dos processos oníricos deverão aguardar como que em uma paragem [Haltestelle] até que elas possam ser anexadas aos resultados de outras investigações que possam abordar o núcleo do mesmo problema de um outro ponto de vista [Angriffspunkte] (FREUD, 2007b, p. 506, grifo do autor).

Assim, embora o caso do sonho de Irma tenha permitido a Freud inferir um domínio novo, uma fundamentação para essas hipóteses 
precisa aguardar até que resultados de estudos de outras formações psíquicas cheguem ao mesmo denominador comum.

Bem, não são exatamente os desempenhos desse aparelho psíquico que estarão na base das diferentes formações psíquicas tematizadas nos textos (psicopatologia cotidiana, chistes, etc.) posteriores à interpretação dos sonhos? Sobretudo os casos clínicos como Dora e Hans não seriam justamente aqueles que anunciam, como modalidades de funcionamento do aparelho psíquico, o domínio da histeria e da neurose infantil?

Portanto, se se pode considerar que o território novo anunciado pelo caso único é o da realidade psíquica, então, é a própria metapsicologia freudiana que emergiria do processamento teórico do material fatual. Uma história clínica teria como função descrever essa elaboração teórica, embora, como disse Freud, saibamos "que não se encontrou nenhum caminho para acomodar de alguma forma, no relato [Wiedergabe], a convicção resultante da análise" (FREUD, 2007c, p. 14).

O que me interessa, então, para finalizar, é registrar alguns dos pressupostos do processo de fabricação de conceitos, conforme concebido por Freud. Antes, convém lembrar duas coisas: 1) que de acordo com o que nos ensinaram os filósofos da ciência (HANSON, 1958), um nome novo ou um conceito novo só se justifica para designar uma realidade nova, um domínio epistêmico novo; e 2) que, segundo Chalmers (1993, p. 111),

a história típica de um conceito, seja ele 'elemento químico', 'átomo', 'o inconsciente' ou qualquer outro, envolve uma aparição inicial do conceito como uma ideia vaga, seguido por seu esclarecimento gradual quando a teoria na qual ele desempenha um papel assume uma forma mais precisa e coerente.

\section{0 caso clínico como lugar de elaboração conceitual do material fatual}

Retomo, então, o parágrafo inicial do texto Pulsões e destinos da pulsão, de 1915, porque considero que nesse texto Freud oferece algumas indicações que nos ajudam a entender como ele pensa o processo de fabricação de conceitos e como entram aí os dados clínicos. 
Como se sabe, a posição de Freud é a de que nenhuma ciência começa a ser construída pela definição de seus conceitos fundamentais. Toda atividade científica, segundo ele, começa com a descrição dos fenômenos, para depois agrupá-los e relacioná-los entre si. Mas, longe de uma posição indutivista ingênua, Freud não pensa essa etapa descritiva e classificatória como observação pura, isenta de hipóteses e ideias iniciais diretoras. Ao contrário, reconhece que já nesse primeiro contato com os fenômenos não é possível evitar a aplicação de certas ideias abstratas. É o que ele escreve: “[...] é inevitável que, já ao descrever o material, apliquemos sobre ele algumas ideias abstratas obtidas não só a partir das novas experiências, mas também oriundas de outras fontes" (FREUD, 1967, p. 145). E mais: justamente essas ideias iniciais é que, mais bem elaboradas, darão corpo aos conceitos básicos de uma ciência, que, a partir daí, passam a guiar a prática posterior. Cito suas palavras: "Tais ideias iniciais - os futuros conceitos básicos da ciência se tornam ainda mais indispensáveis quando mais tarde se trabalha sobre os dados observados" (FREUD, 1967, p. 145).

Na etapa inicial da investigação, porém, essas ideias encontram-se indefinidas e até obscuras, sendo difícil circunscrever e ter claro seu conteúdo. Por essa razão, observa Freud, até que essas ideias sejam tornadas mais claras e precisas, é necessário confrontá-las repetidas vezes com o material empírico, material empírico este que, ao contrário do que pensava o indutivista, apenas aparentemente seria a fonte daquelas ideias iniciais. Na verdade, ressalva Freud, ocorre o inverso. São as ideias iniciais ou as hipóteses de trabalho que tornam possível a observação do material fatual, quer dizer, são as ideias iniciais que possibilitam "enxergar" o que se observa da maneira como o percebemos. Melhor ler as palavras do próprio Freud.

Enquanto elas [as ideias iniciais ou hipóteses] permanecem nesse estado [de indefinição e obscuridade], podemos concordar sobre seu significado remetendo-nos repetidamente ao material experiencial a partir do qual elas aparentemente foram derivadas [dem sie entnommen scheinen]; contudo, na realidade, esse material [experiencial] já estava subordinado a elas [das aber in Wirklichkeit ihnen unterworfen wird] (FREUD, 1967, p. 145, grifo nosso). 
Freud ainda toma o cuidado de ressaltar que, embora essas ideias iniciais tenham o caráter de convenções, isso não quer dizer que são escolhidas ao acaso. Elas são "determinadas pelas relações significativas que mantêm com o material empírico" (FREUD, 1967, p. 145). Obviamente, a vinculação efetiva entre essas ideias iniciais e o material empírico só pode ser afirmada depois, já que no começo o pesquisador só conta com uma crença razoável na pertinência dessa relação. Quer dizer, aquilo que pode vir a ganhar mais tarde o status de conceito começa como uma ideia vaga, como nos ensinou o filósofo da ciência. Por isso, uma formulação mais precisa depende de um estudo paulatinamente mais aprofundado dos fenômenos; só depois disso é que os conceitos básicos de uma ciência podem ser formulados com mais precisão, passando assim a ser amplamente utilizados; só nesse estágio é que os conceitos fundamentais de uma ciência podem ser circunscritos em definições. Mas, ressalva, o progresso constante da ciência não admite definições rígidas, como mostra o exemplo da física; nela, conceitos básicos bem definidos sofrem uma constante modificação em seu conteúdo, conclui Freud.

Eis, portanto, que, ao contrário do que se costuma divulgar, Freud não era nenhum incauto em epistemologia; era, sim, um pensador com um posicionamento epistemológico claro, que nada tem a ver com aquela visão indutivista ingênua que acreditava (e como Arlow também o fez) na possibilidade de se efetuar observações puras, obter dados brutos, isentos de qualquer teoria.

Vale esclarecer que o fato de se dizer que não há observação pura, isenta de teorias, não significa que a experiência da observação e da escuta do analista não sejam importantes e necessárias. Também deve ficar claro, por outro lado, que não se trata de mera aplicação do conceito aos dados de observação. Nem uma coisa nem outra. Afinal, há muito tempo os filósofos da ciência já mostraram que não se pratica uma ciência senão no interior de um paradigma ou a partir de certas expectativas ou interesses. O que estou tentando indicar é que, antes de Popper e Kuhn, Freud já se dava conta dessas condições presentes na base da produção de um conhecimento conceitual da realidade. 


\section{Considerações finais}

Portanto, o argumento de certa corrente da psicanálise de que com o abandono do estudo dos casos clínicos de Freud em favor do uso de registros integrais das sessões de análise teríamos condições de obter dados brutos, mais confiáveis e fidedignos, não leva em conta dois ensinamentos: 1) que os filósofos da ciência há muito demonstraram (desde Hume e Kant, e Popper e Kuhn) a falácia da crença em uma empiria pura, ou seja, na possibilidade de se obter dados de observação em forma bruta; e 2) que, de seu pequeno capital epistemológico, para utilizar uma expressão de Assoun (1981), o próprio Freud já reconhecia o papel decisivo das ideias iniciais e hipóteses de trabalho no processamento do material fatual. Enfim, esquecem-se de que, desde as primeiras elaborações (cf. o problema da autoanálise) em Freud, teoria e prática, metapsicologia e clínica encontram-se soldadas de modo indissolúvel.

Pela mesma razão, embora o relato do caso constitua uma narrativa que em algum grau lança mão de metáforas poéticas, não deve ser, certamente, considerado uma narrativa do tipo literário e, como bem o mostra Rudelic-Fernandez (1999), nem narrativa histórica ou narrativa hermenêutica, já que em sua composição entrariam enunciados observacionais elaborados com a finalidade de descrever uma experiência concreta de análise. Enfim, o caso clínico não deve ser concebido como uma ficção sem maiores qualificativos, porque os enunciados observacionais e a conceituação que entram em sua composição são gerados no interior de uma estrutura teórica aberta e num pensar em movimento.

Nesse sentido, como uma narrativa eminentemente conceitual, o estudo de caso freudiano visa não apenas a descrever-nos o processo de uma experiência clínica, mas, sobretudo, tornar possível ao leitor o acesso aos domínios da realidade epistêmica subjacente à experiência analítica, a realidade psíquica. Por essa razão, não vejo como o discurso freudiano próprio da experiência psicanalítica, dado seu caráter transfenomenal e mesmo contrafenomenal (isto é, a propriedade de avançar para trás daquilo que aparece para localizar aí processos que explicariam o fenômeno, e mesmo, a partir desse plano transfenomenal, 
enunciar teses que contrariam a percepção habitual que temos dos fenômenos) possa ser tomado por uma ficção de caráter vago.

Portanto, de forma isolada, nem a perspectiva ficcionista nem a perspectiva objetivista fariam jus ao caso clínico conforme elaborado por Freud. Além disso, pelas características do processo de elaboração conceitual descrito por Freud, devemos considerar que, além de hipóteses de trabalho e outros conceitos já formulados, outros fatores devem fazer parte do processamento teórico do material clínico. Esses fatores são, em última instância, da ordem do inconsciente do analista, de modo que parece não ser fora de propósito cogitar, analogamente ao trabalho do sonho na elaboração onírica, uma espécie de "trabalho do caso", como o faz Rudelic-Fernandez (1999), a operar na elaboração do relato do caso clínico. Se for assim, a compreensão do sentido e do papel do caso clínico na psicanálise freudiana tem como condição necessária a própria metapsicologia.

\section{Referências}

ASSOUN, P.-L. Introduction à l'épistemologie freudienne. Paris: Payot, 1981. CHALMERS, A. O que é ciência afinal? São Paulo: Brasiliense, 1993.

EDELSON, M. Hypothesis and evidence in psychoanalysis. Chicago: The University of Chicago Press, 1984.

EDELSON, M. Psychoanalysis: a theory in crisis. Chicago: The University of Chicago Press, 1988.

FREUD, S. Triebe und Triebschicksale. In: FREUD, S. Sigmund Freud Gesammelte Werke. Frankfurt: S. Fischer, 1967.

FREUD, S. A correspondência completa de Sigmund Freud para Wilhelm Fliess, 1887-1904. Rio de Janeiro: Imago, 1986.

FREUD, S. Señorita Elisabeth Von R. (Freud). In: FREUD, S. Obras completas. Buenos Aires: Amorrortu, 2007a. 
FREUD, S. La interpretación de los sueños. In: FREUD, S. Obras completas. Buenos Aires: Amorrortu, 2007b.

FREUD, S. De la historia de una neurose infantil. In: FREUD, S. Obras completas. Buenos Aires: Amorrortu, 2007c.

HANSON, N. R. Patterns of discovery: an inquiry into the conceptual foundations of science. Cambridge: Cambridge University Press, 1958.

HAYNAL, A. A técnica em questão: controvérsias em psicanálise de Freud e Ferenczi a Michael Balint. São Paulo: Casa do Psicólogo, 1995.

HONDA, H. O caso clínico e a constituição da metapsicologia freudiana. In: LEITE, N. V. de A.; TROCOLI, F. (Org.). Um retorno a Freud. Campinas: Mercado de Letras; FAPESP, 2008.

MAHONY, P. J. Quelle valeur accorder aujoud'hui aux cas de Freud? In: FÉDIDA, P.; VILLA, F. (Org.). Le cas en controverse. Paris: PUF, 1999.

RUDELIC-FERNANDEZ, D. Langage du cas: modeles et modalités. In: FÉDIDA, P.; VILLA, F. (Org.). Le cas en controverse. Paris: PUF, 1999.

SOUZA, E. L. A. de. (A vida entre parênteses): o caso clínico como ficção. Psicologia Clínica, v. 12, n. 1, p. 11-20, 2000.

WIDLÖCHER, D. Le cas, au singulier. Nouvelle Revue de Psychanalyse, n. 42, p. 285-302, 1990.

WIDLÖCHER, D. Um caso não é um fato. In: WIDLÖCHER, D. Livro anual de psicanálise X. São Paulo: Escuta, 1996.

WIDLÖCHER, D. La méthode du cas unique. In: FÉDIDA, P.; VILLA, F. (Org.). Le cas en controverse. Paris: PUF, 1999. p. 191-200.

Recebido: 16/09/2010

Received: 09/16/2010

Aprovado: 10/03/2011

Approved: 03/10/2011 